\title{
sciendo
}

\section{Investigating students' use of official statistical data}

\author{
Constanța MIHĂESCU \\ The Bucharest University of Economic Studies, Bucharest, Romania \\ constanta.mihaescu@csie.ase.ro \\ Adrian OȚOIU \\ The Bucharest University of Economic Studies, Bucharest, Romania \\ adrian.otoiu@csie.ase.ro \\ Alina PROFIROIU \\ The Bucharest University of Economic Studies, Bucharest, Romania \\ alinaprofiroiu@yahoo.com \\ Ileana Niculescu-ARON \\ The Bucharest University of Economic Studies, Bucharest, Romania \\ gabriela.niculescu@csie.ase.ro
}

\begin{abstract}
This paper presents the perceptions of social science students about the use of official statistical data, in the context of active learning of Statistics, and other topics related to Applied Statistics. In order to make these courses more attractive, and to challenge and stimulate statistical education, our students work on projects in which they use official statistical data to explore practical, real-life issues. Their attitudes and perceptions regarding official statistical data sources are very important, both for acquisition of statistical analysis skills, essential for their future professional life, and for improvement of the official data sources. Therefore, we conducted a custom-made survey among students from Romanian higher education institutions (HEIs) and gathered a database with 334 responses, which allowed us to identify the main characteristics, problems and solutions concerning the use of statistical official data sources by university students.
\end{abstract}

Keywords: official statistical data sources, statistical analysis skills, descriptive statistics, statistical learning, active learning, National Institute of Statistics, Eurostat.

\section{Introduction}

The teaching of Statistics in Social Sciences in higher education institutions (HEIs) has a long tradition in Romania. Statistical analysis skills are increasingly important, due to the strong development of information and communications technology (ICT). The acquisition of competencies in statistical analysis is achieved through graduation of several courses, such as Descriptive and Inferential Statistics, Multidimensional Statistical Analysis, Econometrics, and applied subjects such as Demography, Time Series, Sampling and Statistical Surveys, Nonparametric Statistics, Financial Market Statistics etc.

In order to develop statistical reasoning skills and promote active learning, seminars should be designed so as to involve students in data collection and data analysis for decisionmaking. The data sets used in the majority of the above-mentioned statistical topics are taken 
from the official sources as the National Institute of Statistics (INS) of Romania, Eurostat. National Bank of Romania, World Bank etc.

Data collection is an important phase for the students' awareness and critical thinking about reliable statistics. Usually, the students in Social Science have to work on a project using official statistical data, which provide them an experience close to using data analysis in a real-life, professional setting. In this context, their attitudes and perceptions regarding these data sources are very important, both for acquisition of skills and knowledge in statistical analysis, essential in their future professional life, and for fostering student's innovative ideas which can improve the official data sources.

In order to identify the students' perceptions of official statistical data use, we conducted a custom-made survey among students from Romanian higher education institutions (HEIs) and gathered a database with 334 responses. These allowed us to present the main characteristics, problems and solutions of students' needs of official statistical data.

\section{Literature review}

Until now, the students' attitudes and opinions regarding the usefulness and reliability of statistical data used in their work have not been studied, despite the urge of a statistical critical thinking and the right use of quantitative data in policy making.

Related literature examines different approaches to teaching Statistics, different pedagogical methods and experiments to promote active learning, or various designs for statistical learning for teachers.

Most authors propose an attractive design for Statistics courses that could stimulate, challenge, and even entertain the students, in order to fight against the pre-conceptions that the topic is boring, or refers only to lies. They "argued for making statistics relevant to real life and for using computers in our teaching", and promoted "critical thinking, the analysis of real data, and use of modern technology" (Murphy, 2006).

A modern concept - communities of practice - reinforced the reforms in teaching statistics, relating to the design of teachers' statistical learning. According to this, learning is a "matter of negotiation of meanings that involves the interaction of two constituent processes: participation and reification" (Wenger,1998, p.96, citing Gomez-Blancarte and Viramontes, 2014). In this context, it is important for teachers to give meaning to educational reifications by integrating it with participation in the practice of teaching (Gomez-Blancarte and Viramontes, 2014).

The content of specialized statistical training is also very important, due to increase of demands of statistics education for the general citizen. Teachers' professional development underlines the need of collaboration between statisticians and mathematics educators to prepare teachers to teach statistics (Batanero and Diaz, 2010).

Brophy and Hahn (2014) highlighted the importance of using real data in teaching statistics through in-class experiments with large groups of students. The resulting data set served as a teaching tool to illustrate various potential topics.

In New Zealand, the importance of official statistics to government policy is so great that it is becoming essential to have skills to evaluate the relative quality of available official data. Official statistics influence the government policies and these policies impact the individuals' lives. In this context, students are encouraged to use, as well as understand and therefore avoid misuse of official statistics (Janssen and Forbes, 2014). 


\section{Methodology}

For investigating the use of official statistical data by Romanian Social Science students, data was collected using a custom-made survey. The survey targeted university students from Romanian higher education institutions (HEIs), and consisted of 22 thematic questions, of which two were screening questions, and 6 socio-demographic questions.

Dissemination of the questionnaire was done using several academic and research networks. More specifically academic staff from major universities helped distribute survey links via email, and so did members of the Romanian Statistical Society. Members of the Doctoral Schools had a high level of involvement. In addition, private social media groups on Facebook were used to disseminate the survey information and links for classes from 2018/19 academic year onwards. Data collection period was May 20th 2019- June 2th, 2019, during which a sample of 334 observations was obtained.

\section{Respondents at a glance}

The answers for the socio-demographic questions reveal a rather diverse base of respondents. While about $85 \%$ of the respondents were Social Science students of the Bucharest University of Economic Studies, with other students for A.I Cuza University from Iași, Babeș-Bolyai University from Cluj and West University of Timisoara, they came from a wide variety of faculties in terms of major fields of study.

Because the degree of specialization within the faculties varied, from highly focused areas such as Public Administration, Economics, Finance, Management, to more general areas such as Business Administration in Foreign Languages, or Economics and Business Administration, we have grouped the answers to fit broader fields of study. Our aim was to both showcase the diversity of the specializations, and group the characteristics of the fields of study into broader categories based on their affinities. Thus, Economics and Business Administration students from Iasi and Cluj were grouped together with Theoretical and Applied Economics students for Bucharest, while students from the Business Administration in foreign languages, Management, and Tourism faculties in Bucharest were considered to follow a more applied curriculum. The Other majors category include students from Finance, Accounting and Management Information Systems, International Relations, Doctoral Schools, and Other faculties, based on their low number of responses and heterogeneity of specializations.

Among the major fields of study, Public Administration students represented a little over half of the respondents. The other half was rather diverse, with majors raging from Cybernetics, Informatics and Statistics students (16\%) to Economics and Business Administration majors (12\%). Agrifood and Environmental Economics students were the third largest group of students with specialized majors. 


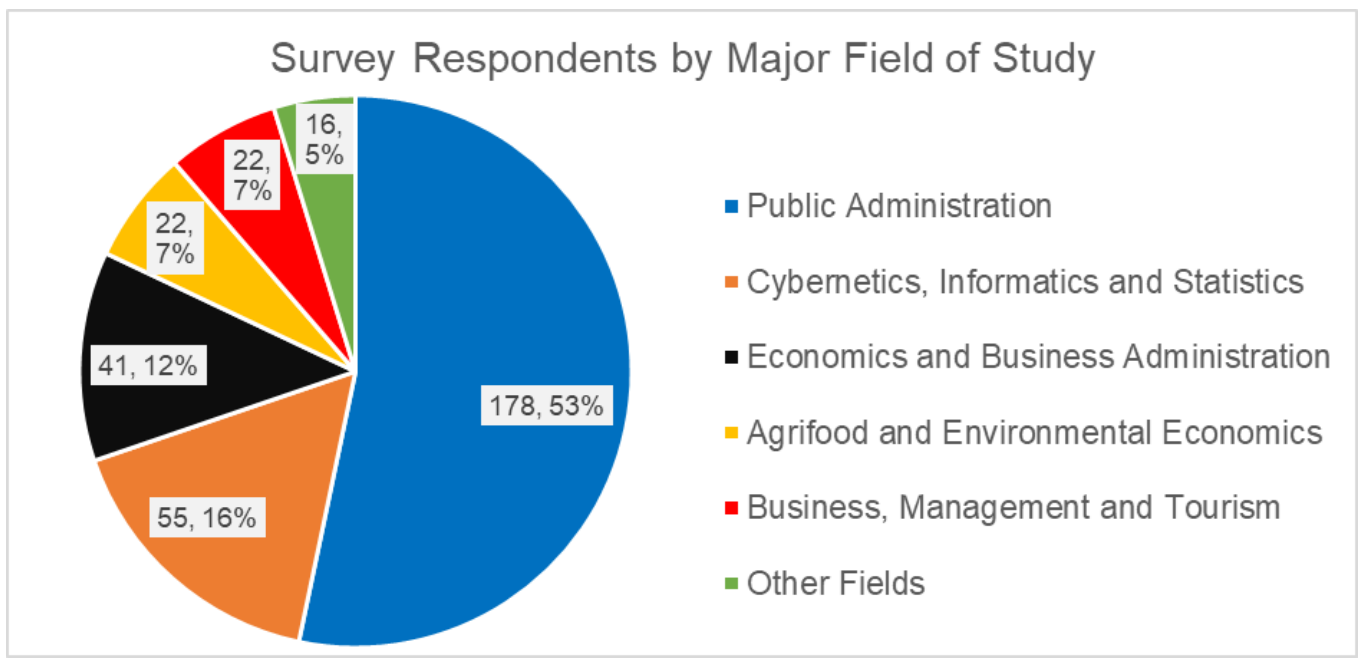

Figure 1. Structure of respondents by broader fields of study

Source: Survey results and authors' calculations

Almost three quarters of respondents were bachelors students. Of the remaining $25.4 \%$ respondents, $70 \%$ of graduate students were Master's students, with the remaining being PhDs. The majority of the students were in the $2^{\text {nd }}$ year of studies, with about one third being in their first year of study. Over 4/5ths of the students were women.

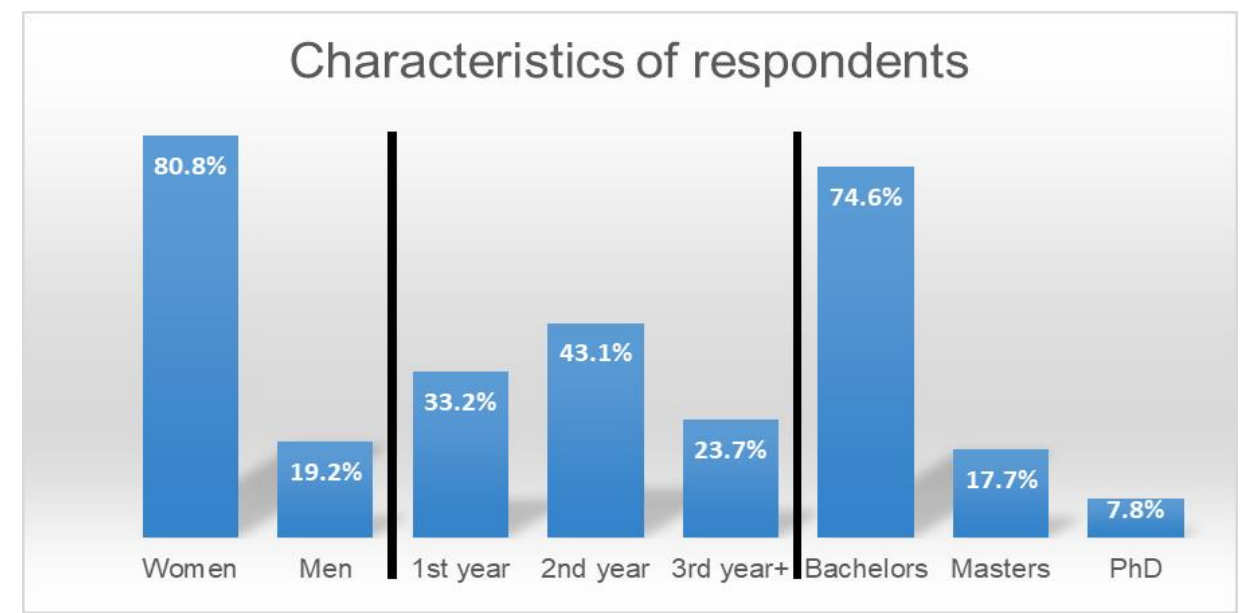

Figure 2. Diversity among the students who answered the survey

Source: Survey results and authors' calculations

\section{Survey results and discussion}

The survey looked at particular aspects of the use of official data by Social Science students. The focus was on what data sources are most known and used, how frequently they were used, and the main uses of official data. Frequency of use, the socio-economics fields examined/researched, and the subjects with intensive use of official data were also explored. The perception and satisfaction of the respondents with regards to official data was also inquired. 


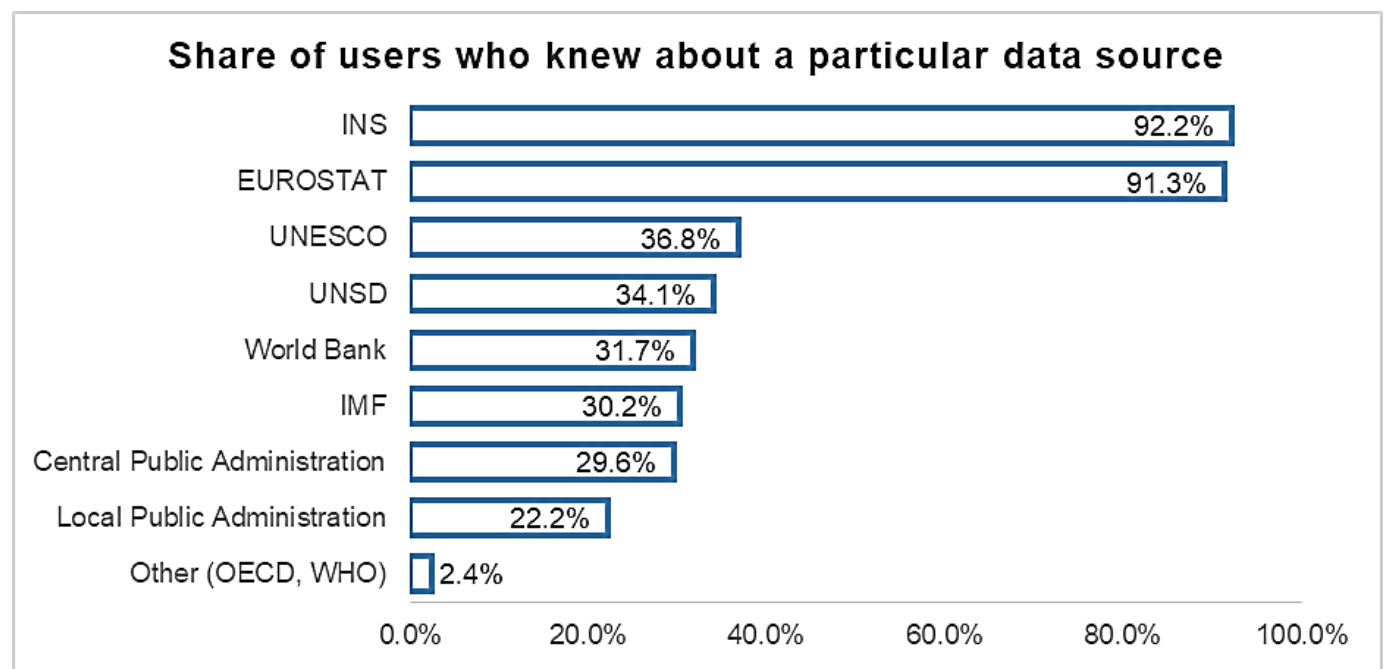

Figure 3. Knowledge of official data sources

Source: Survey results and authors' calculations

Results showed that almost all users had knowledge about the Romanian National Statistical Institute (INS) and EUROSTAT (Figure 3). Around a third knew about international sources of official data, IMF, World Bank and the UN statistical data. Less than 30\% knew about official data available from Central public administration (CPA) and Local public administration (LPA). Other data sources, such as OECD or WHO, were virtually unknown.

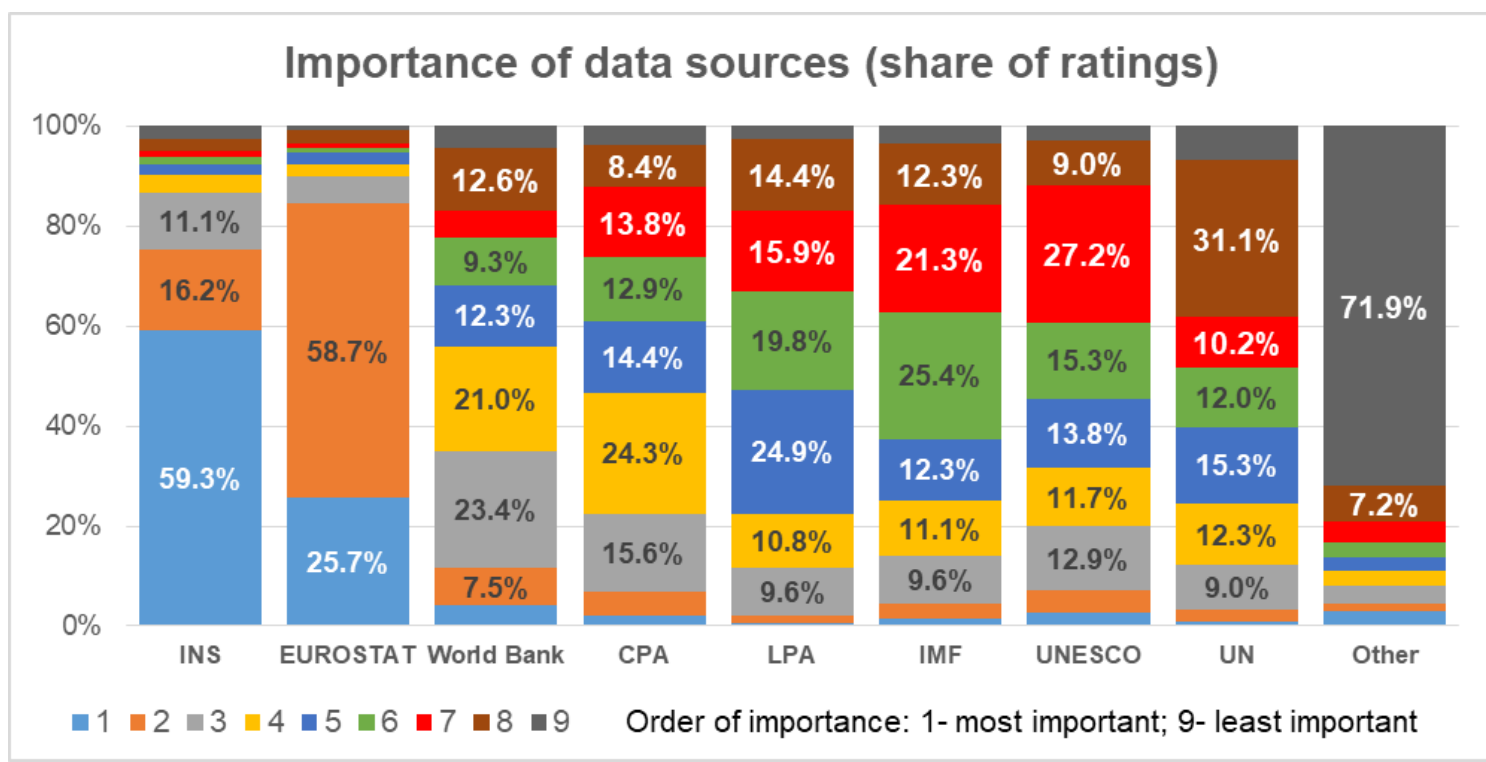

Figure 4. Ranking the importance of official data sources

Source: Survey results and authors' calculations

A more detailed picture is given by the importance given for each data source, on a scale from 1 to 9. In Figure 4, we see that INS is, by far, the most important data source, while EOROSTAT was the second most important data source. It appears that users of both INS and Eurostat data used other data sources as well, which were perceived as less important sources of information. Thus, World Bank data was identified as the third most important 
source by $23.4 \%$ of the respondents. While no more than $30 \%$ of respondents used CPA and LPA data, they were ranked as being more important than IMF, UNESCO, and UN data, which were identified as the $6^{\text {th }}$ to $8^{\text {th }}$ most important sources of data.

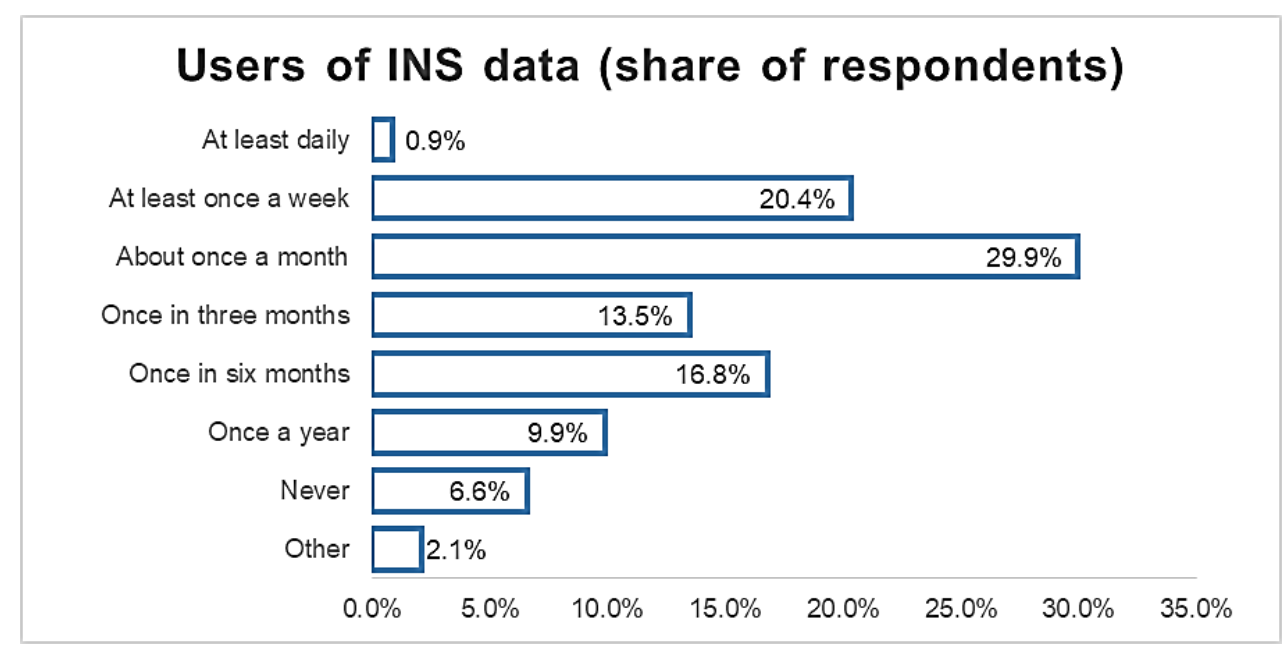

Figure 5. Frequency of INS data usage

Source: Survey results and authors' calculations

With respect to the most important data source, INS, 79\% of respondents report that they learned about it from university professors. Another $8 \%$ knew about if from high school, and other $7 \%$ found it out from internet search.

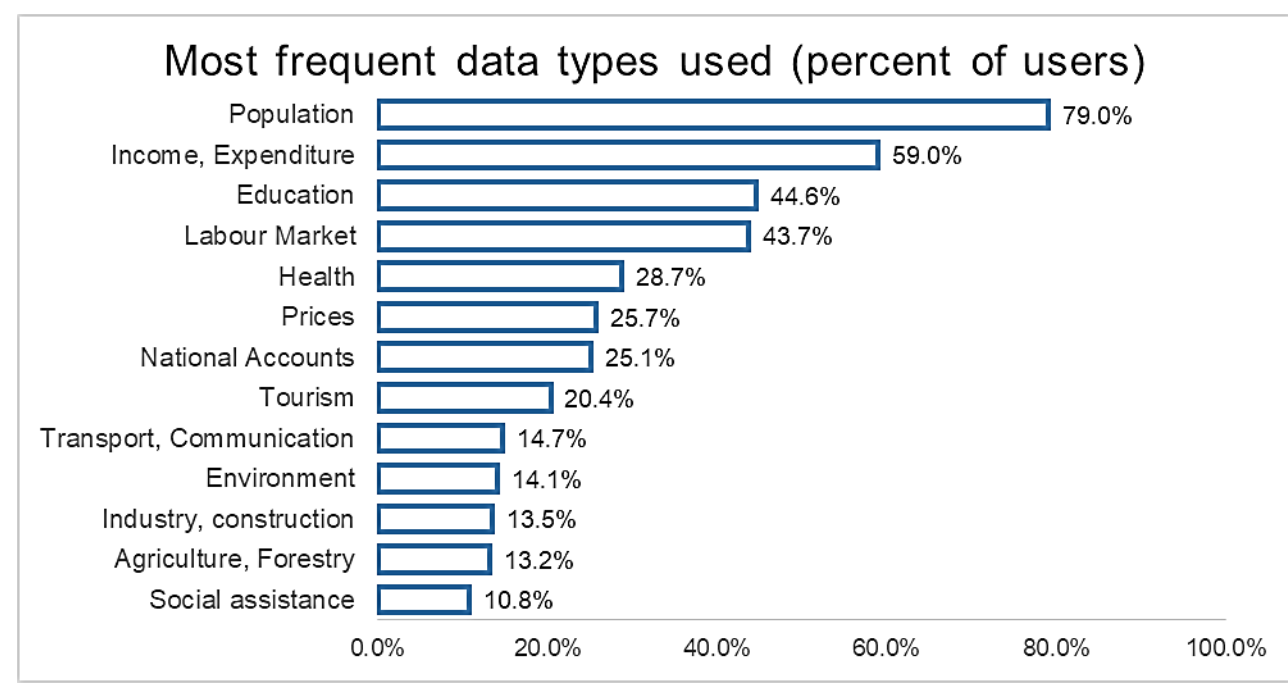

Figure 6. INS data usage by field

Source: Survey results and authors' calculations

The use of INS data is fairly frequent; over half of the respondents claim using it at least once a month. Another $40 \%$ use it at least once a year, but less frequent than once a month. A minority of $6.6 \%$ users of data claim no use of INS data.

INS social and related data was the most frequently accessed. More than half of the student users accessed Population data, and Income and Expenditure data. Around 44\% 
looked up Education and Labour market data. Health, Prices, and National accounts data were used by over $25 \%$ of the users.

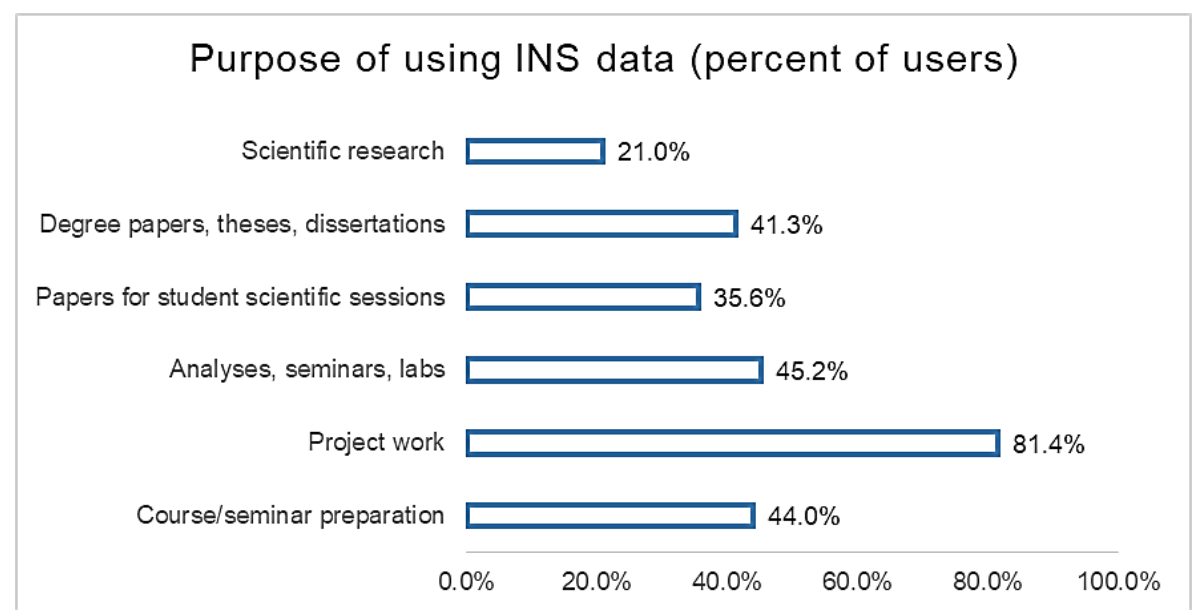

Figure 7. Main purposes for using INS data

Source: Survey results and authors' calculations

While a high percentage of student users used INS data, most of it was to do project work, as requirements for specific courses taken. Less than half used INS data for coursework preparation, degree papers (including PhD theses and dissertations), and analyses. The use for research was, however, fairly limited given the fact that, in many cases, business and economics research involves the use of data to draw conclusions (Figure 7).

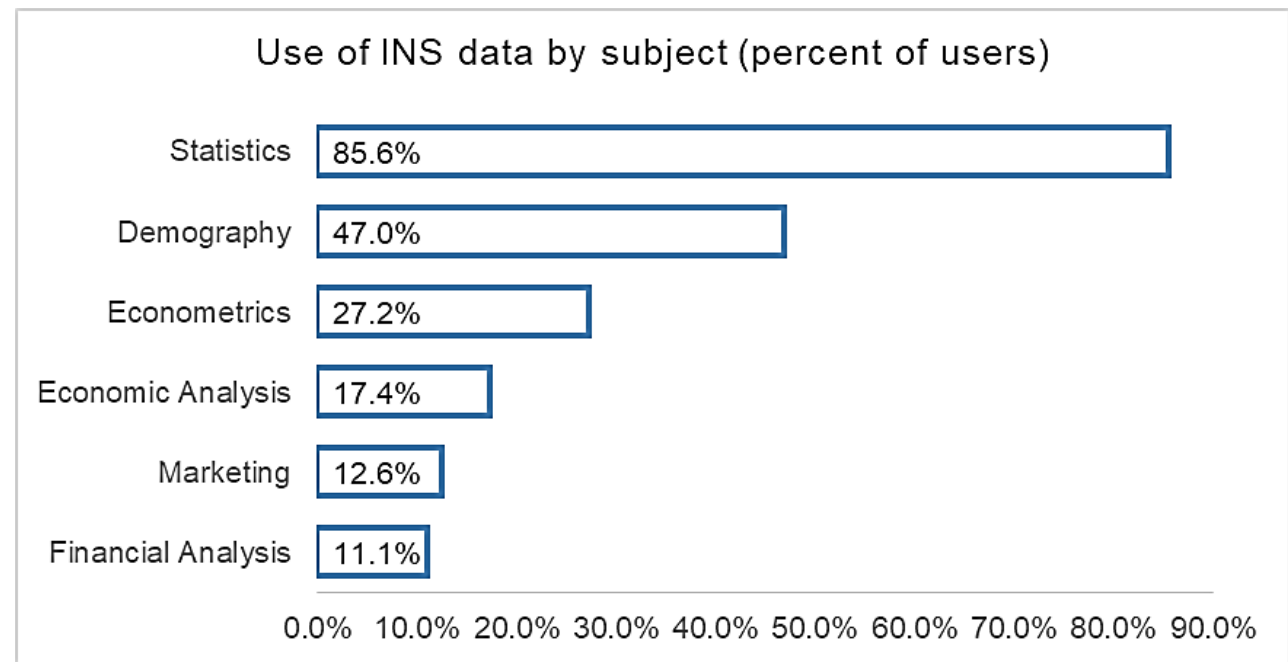

Figure 8. Subjects where students use INS data

Source: Survey results and authors' calculations

In most cases, INS data was used in fulfillment of the requirements of Statistics classes. Half of student users reported using INS data for Demography classes. For other subjects, the use was rather limited, perhaps due to the use of more specialized data sources (Figure 8). 
User satisfaction regarding INS data was fairly good, with average marks between 8 and $9^{1}$, for all dimensions analyzed, namely online publications, statistics by theme, regional yearbooks, visualization tools, news, EU policy indicators, economic trends, and online databases. When users were asked to identify areas of improvement of INS services, they mainly pointed out to improving the functionality and user-friendliness of the web site (46 users), increased frequency of updates (32 users), and having more detailed data available (10 users).

EUROSTAT data was ranked the second most important by student users. In terms of how users found out about it, the situation is similar to INS data. Most users found about it from university professors (77\%), with another $9 \%$ from high school professors. Only $6 \%$ found out about it by themselves.

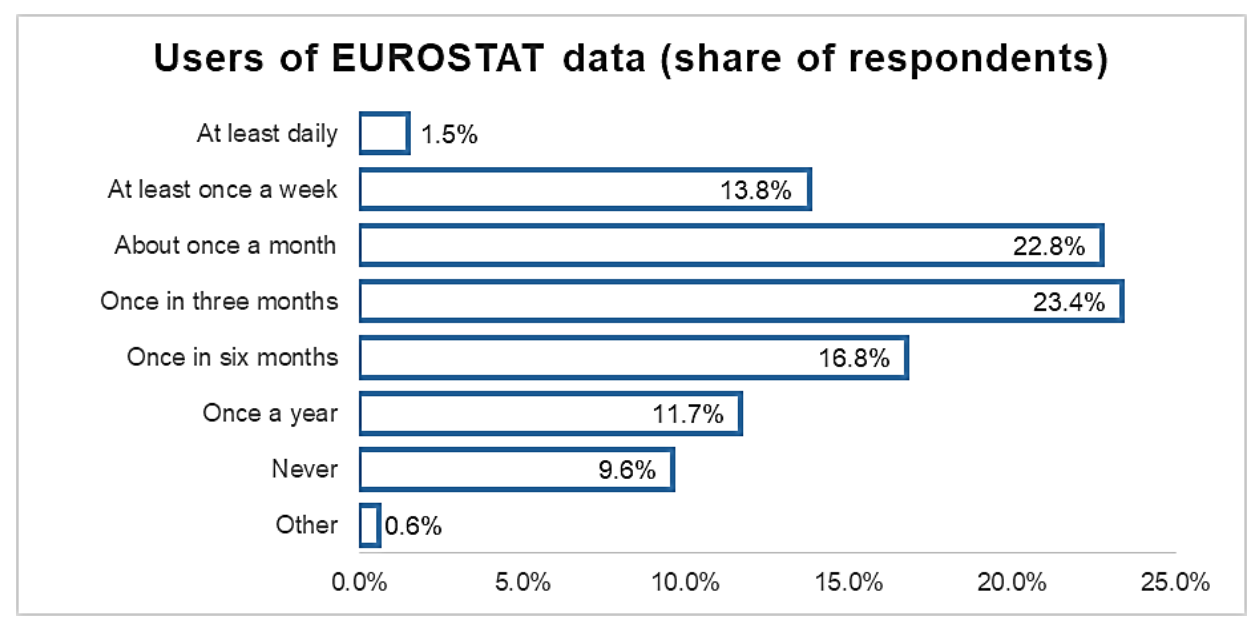

Figure 9. Frequency of EUROSTAT data usage

Source: Survey results and authors' calculations

With respect to frequency of use, the distribution of EUROSTAT users was more even compared with INS ones. Only $38.1 \%$ used the data at least one month or more often. In most cases (40.2\%), data was used at least once in six months, but less often than once a month. $9.6 \%$ of student users claim to have never used EUROSTAT as a source of data.

Uses of EUROSTAT data were also more evenly spread, in addition to being more diverse. While the fields/categories of data were mostly the same as for INS data, their use was less frequent for the first categories, up to and including National Accounts, as shown in figure 10 . However, data from these fields was used by more than $25 \%$ of the respondents.

\footnotetext{
${ }^{1}$ Marks ranged from 1 (very unsatisfied) to 10 (very satisfied).
} 


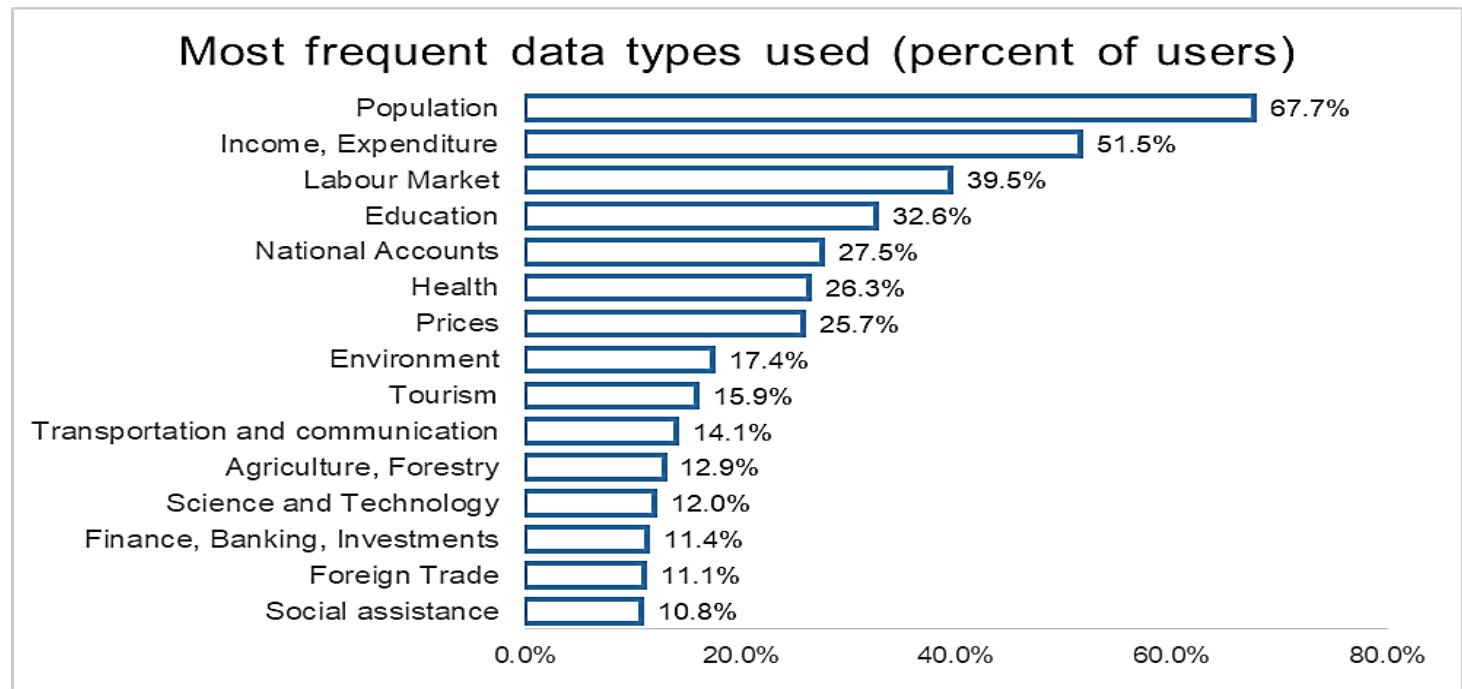

\section{Figure 10. EUROSTAT data usage by field}

Source: Survey results and authors' calculations

A higher proportion of use for the last categories, Environment, Science and Technology, Finance, Banking and Investments, and Foreign Trade, was reported for users of EUROSTAT data. Thus, while being the second data source, use of EUROSTAT data was more diversified.

\section{Purpose of using EUROSTAT data (percent of users)}

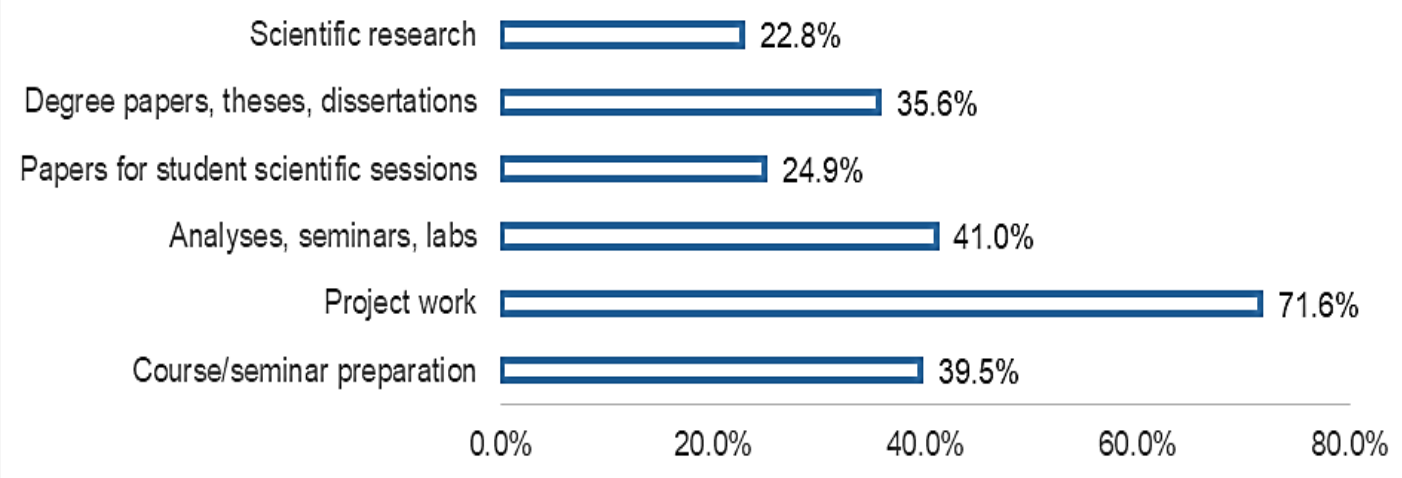

Figure 11. Main purposes for using EUROSTAT data

Source: Survey results and authors' calculations

Being the second source of data used, the proportion of use of EUROSTAT data for specific purposes was, in general, lower than for INS data (Figure 11). The highest differences, of over 10 percentage points, were reported for project work, and papers for student scientific sessions. In most other cases, differences were around 4 to 5 percentage points. The only exception was the use for scientific research, for which EUROSTAT data was slightly higher. 


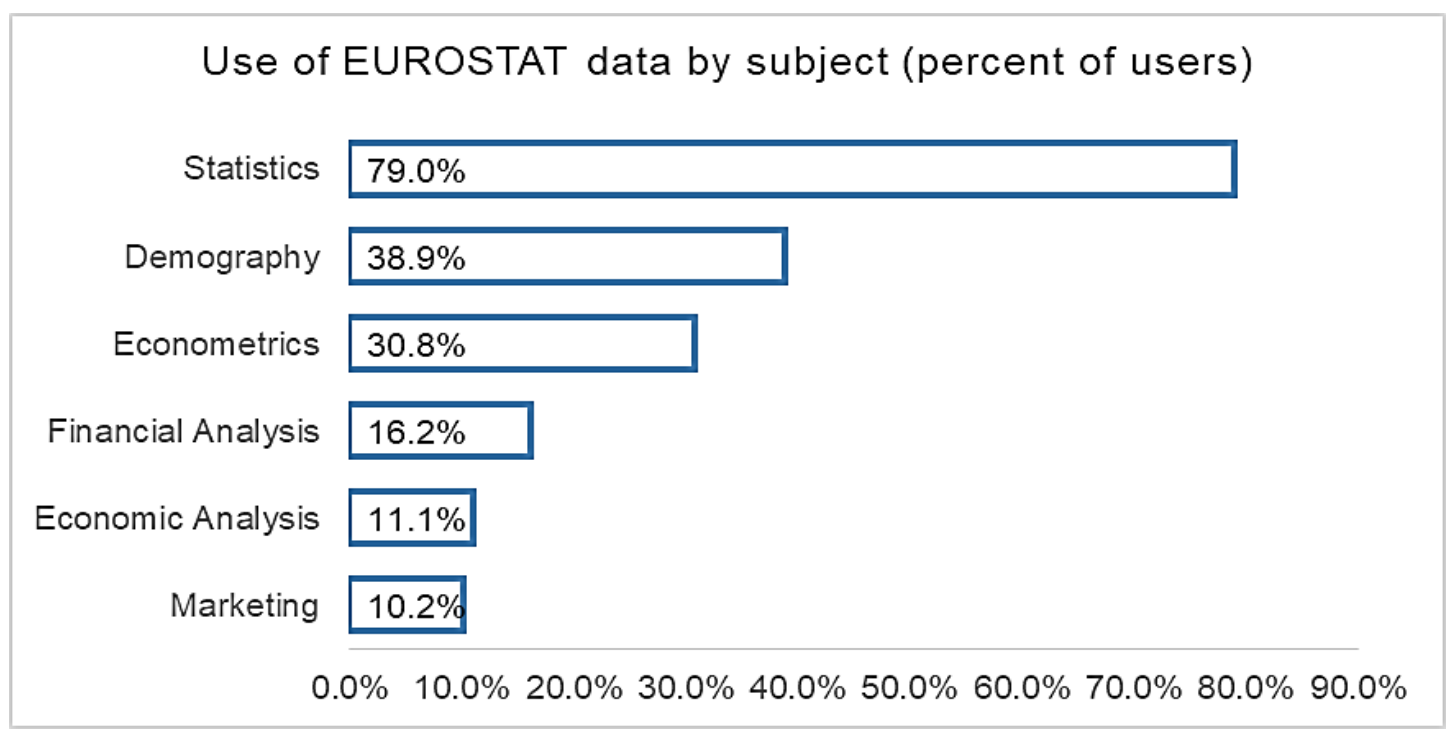

Figure 12. Subjects where students use EUROSTAT data

Source: Survey results and authors' calculations

Use by subject was similar to the one reported for INS, with Statistics, Demography and Econometrics coming on top. However, Econometrics and Financial analysis classes made significantly more use of EUROSTAT data, perhaps because it referred to several countries.

User satisfaction regarding EUROSTAT data was also fairly good, with average marks between 8 and $9^{2}$, for all dimensions analyzed, namely online publications, statistics by theme, regional yearbooks, visualization tools, news, EU policy indicators, economic trends, and online databases.

When users were asked to identify areas of improvement of EUROSTAT services, a few users indicated improvement of the functionality and user-friendliness of the web site (15 users), increased frequency of updates (13 users), and having more detailed data available (11 users).

A sizable part of the survey was devoted to the use of microdata, as a detailed version of the summarized, tabular data that is usually retrieved by users of official statistical data. Microdata represents data reported at unit level, and is used for performing in-depth analyses, usually involving econometric and data mining techniques.

However, knowledge and use of microdata was found to be rather limited. Only 29\% of respondents claimed they needed microdata, with about one third reporting not knowing about it.

\footnotetext{
${ }^{2}$ Marks ranged from 1 (very unsatisfied) to 10 (very satisfied).
} 


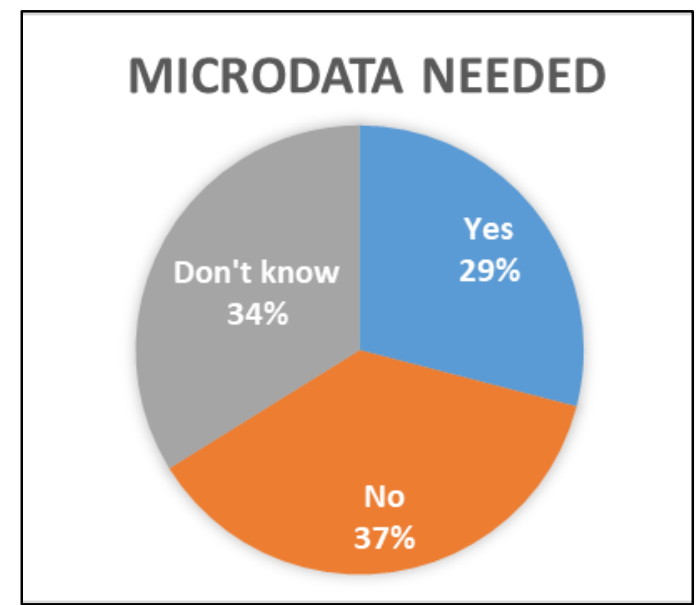

Figure 13. Share of users reporting microdata neeeds

Source: Survey results and authors' calculations

In spite of the low numbers of users who claimed they need microdata, a significant number of respondents managed to obtain it from either INS and/or Eurostat. The combined total of users who obtained microdata is $28.7 \%$. A small but significant number of users did not obtain requested microdata, despite requesting it.

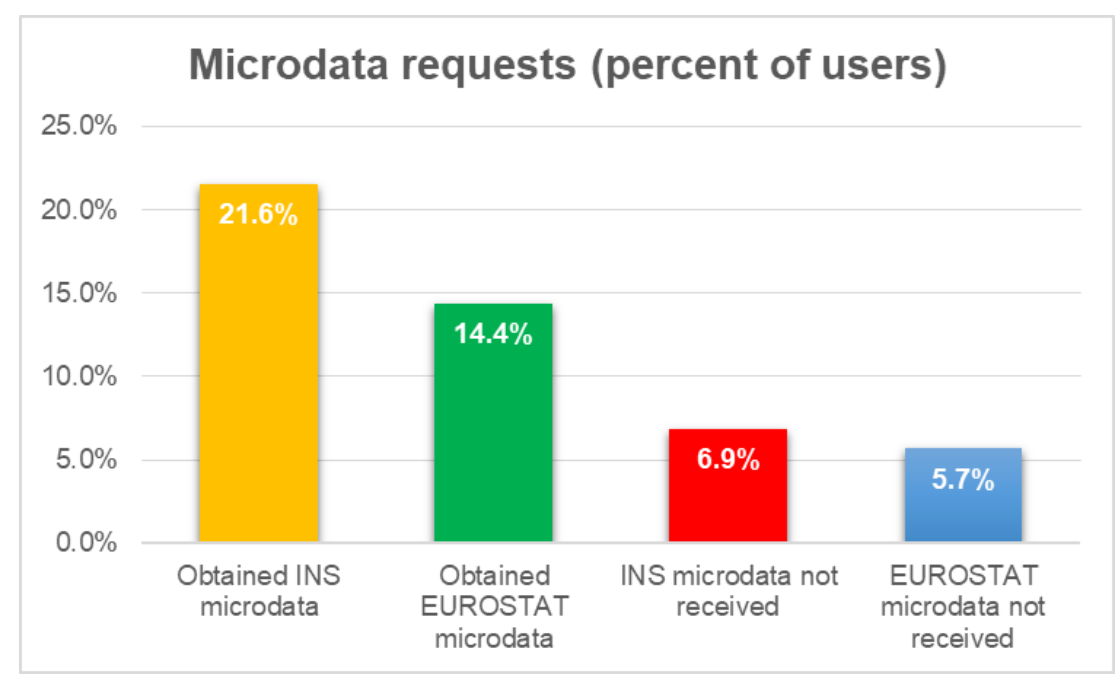

Figure 14. Status of microdata requests

Source: Survey results and authors' calculations

The feedback from those who requested microdata from INS (regardless of the fact that they received it or not), shown in Figure 15, is mixed. While many claimed access was easy, over a quarter say procedures were bureaucratic, and about one fifth perceived the process of obtaining microdata as being difficult. 


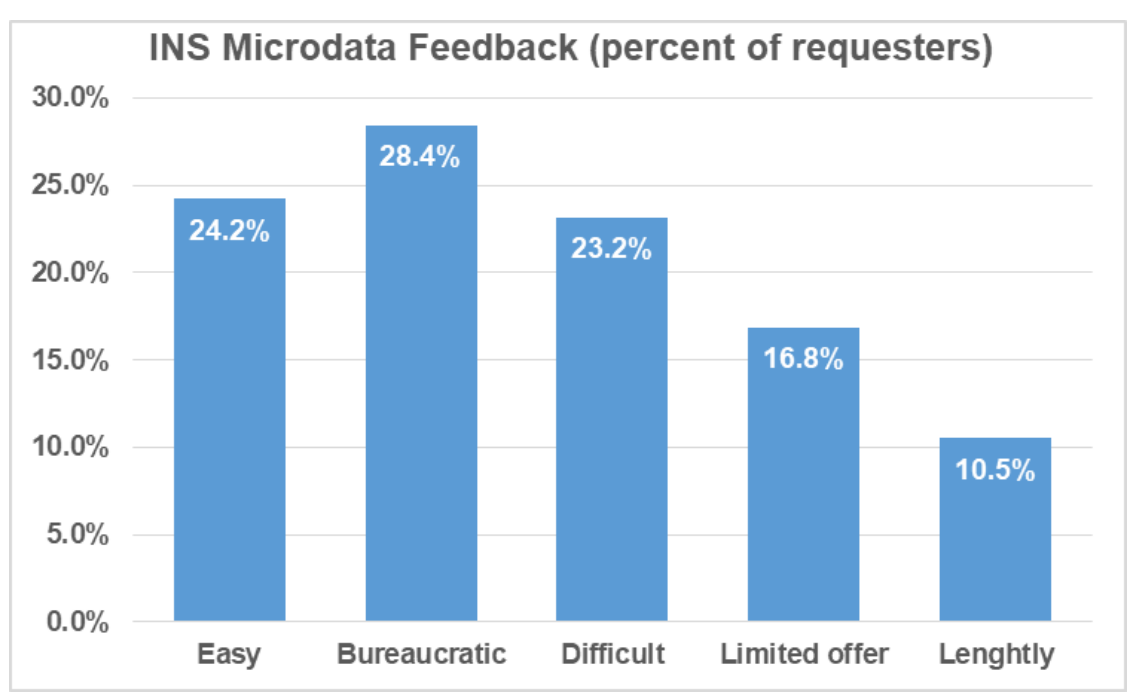

Figure 15. Feedback about access to INS microdata

Source: Survey results and authors' calculations

About one tenth perceived the process as being lengthy, with another one sixth feeling that the microdata available was limited in scope.

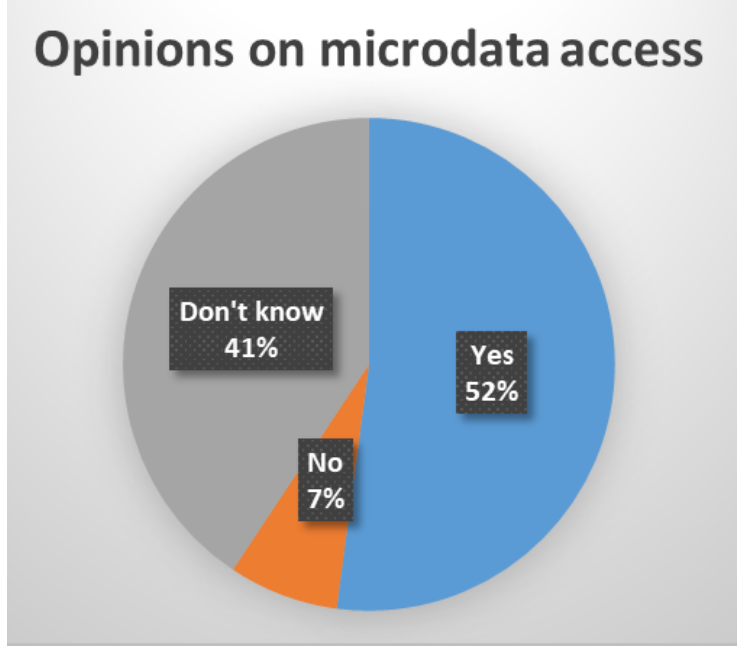

\section{Figure 16. Opinions concerning access to microdata}

Source: Survey results and authors' calculations

This feedback appears less satisfactory if we consider the fact that most student users consider that microdata should be freely accessible, while only a minority consider that access to it should be restricted.

\section{Conclusion}

The survey paints a diverse picture of the use of official statistics by university students through completing their coursework and/or degree requirements.

Most of them are familiar with INS and Eurostat data sources, which account for being the most important data sources. Other official data sources (World Bank, IMF, UNESCO, UN 
Statistical Division) are known only by $30-38 \%$ of the respondents. Public administration data, is less known, but counts as being the most important sources after INS, Eurostat and World Bank data. Over half of the respondents used INS data at least once a month, compared to a little over one third in the case of Eurostat data. The types of data used were fairly similar for both data sources; however, Eurostat data was more often used to retrieve National Accounts data.

Project work was by far the main purpose for using INS and Eurostat data. However, the share of respondents using this data for other purposes was significantly lower. This is a rather unsatisfactory result, as less than half of the respondents appear to use either data for other purposes, including course and seminar work.

It seems most students were using INS and Eurostat data in Statistics classes. Demography classes come second, followed by Econometrics classes. Results may not only be disappointing for other subjects, such as Economic Analysis, Marketing, or Financial analysis, but even for Demographics and Econometrics, if we consider the fact that less than half of the students use any, or both data sources during coursework. The fact that most users had rather high satisfaction levels with respect to getting and using data from both sources suggests that availability and ease of use was not the cause of relatively low levels of use for many data-intensive subjects.

Knowledge of microdata, and its availability is rather low. Fewer than a third of respondents claimed they needed microdata, and about the same percentage received it. About three thirds of those who attempted to get INS microdata claimed that the process was rather difficult, lengthy or long. This contrasts with the opinion that microdata access should be open, expressed by more than half of the respondents.

Taken together, results show that use of official data is rather extensive only when it comes to coursework, and for courses which specifically require it. Perhaps more should be done in terms of getting students to use official data on a regular basis, more frequently for activities such as research and degree papers.

\section{Acknowledgements}

The authors would like to thank for their support: Tudorel Andrei from National Institute of Statistics Romania; Monica Roman, Zizi Goschin, Daniela Șerban and Raluca Căplescu, from Statistics and Econometrics Department, Buharest University of Economic Studies; Mihai Roman and Vergil Voineagu, from the Doctoral School of the Bucharest University of Economic Studies; Codruța Mare from Babes Bolyai University (Cluj); Ciprian Șipoș from West University (Timisoara); Mariana Hatmanu and Laura Asandului from Alexandru Ioan Cuza University (Iasi). They would also like to thank the university students who participated in the survey.

\section{References}

Brophy, C., Hahn, L. (2014), Engaging Students in a Large Lecture: An Experiment using Sudoku Puzzles, Journal of Statistics Education, Volume 22, Number 1, http://jse.amstat.org/v22n1/brophy.pdf

Batanero, C., Díaz, C. (2010), Training teachers to teach statistics: what can we learn from research?, Statistique et Enseignement, 1(1), 5-20, http://www.statistique-etenseignement.fr, http://webcache.googleusercontent.com/search?q=cache:_dQqRTcp8ewJ:statistique -et-enseignement.fr/article/view/3/1+\&cd=5\&hl=ro\&ct=clnk\&gl=ro 
Gómez-Blancarte, A., Viramontes, I.M. (2014), Communities of practice: a theoretical framework to design for teachers' statistical learning, Conference: International Conference on Teaching Statistics (ICOTS 9),

https://www.researchgate.net/publication/273773664_communities_of_practice_a_ theoretical_framework_to_design_for_teachers'_statistical_learning

Janssen, T., Forbes, S.. (2014), The use of official statistics in evidence based policy making in New Zeeland, ICOTS9, Invited paper, https://icots.info/9/proceedings/pdfs/ICOTS9_5A1_FORBES.pdf

Murphy, P. (2006), A non-standard approach to teaching an introductory statistics course to social science students, ICOTS-7, https://www.researchgate.net/publication/252819550_a_nonstandard_approach_to_teaching_an_introductory_statistics_course_to_social_science_ students 